\title{
O CAVING COMO ATIVIDADE DE AVENTURA E LAZER NA NATUREZA
}

Recebido em: 17/02/2011

Aceito em: 28/10/2011

\author{
Marilda Teixeira Mendes ${ }^{1}$ \\ Universidade Federal de Minas Gerais - UFMG \\ Belo Horizonte - MG - Brasil \\ Francisco José Andriotti Prada ${ }^{2}$ \\ Junior Vagner Pereira da Silva ${ }^{3}$ \\ Tânia Mara Vieira Sampaio ${ }^{4}$ \\ Universidade Católica de Brasília - UCB \\ Brasília - DF - Brasil
}

RESUMO: O estudo teve como objetivo analisar as contribuições do caving na experiência de relações humanas e ecossistêmicas como atividade de aventura e lazer na natureza. Um estudo qualitativo, utilizando-se de entrevista semi-estruturada. Participaram dez praticantes profissionais do Espeleogrupo Peter Lund-EPL. Os resultados indicaram que o caving proporciona um processo intenso de integração ser humano-natureza re-significando a experiência de relação com as pessoas e o mundo. Outro aspecto relevante foi o conhecimento de um ambiente muito distinto, mas, sobretudo a experimentação de diversas emoções como medo, riscos, tranqüilidade, paz. A vivência oportuniza momentos de introspecção, de contemplação, de silencio, mas também de solidariedade, sociabilidade, consciência da necessidade de preservação do ambiente.

PALAVRAS CHAVE: Atividades de Lazer. Esportes. Natureza.

\section{CAVING LIKE ACTIVITY IN NATURE ADVENTURE AND LEISURE}

ABSTRACT: The present study aimed to analyze the contributions of caving to human relationships and ecosystem experiences such as nature adventures and leisure activities. Ten professionals from the Peter Lund Speleogroup - ELP, participated in this qualitative study, which used a semi-structured interview. The results indicate that caving promotes an intense man-nature integration process, bringing up a new meaning

\footnotetext{
${ }^{1}$ Mestre em Educação Física, Docente no Instituto de Ciências Agrárias da Universidade Federal de Minas Gerais - ICA/UFMG.

${ }^{2}$ Doutor em Biologia Funcional e Molecular, Docente no Programa de Graduação e Pós-Graduação Mestrado e Doutorado em Educação Física da Universidade Católica de Brasília.

${ }^{3}$ Doutorando em Educação Física pela Universidade Católica de Brasília, Bolsista CAPES/PROSUP.

${ }^{4}$ Doutora em Ciência da Religião, graduada em Pedagogia, Docente no Programa de Graduação e PósGraduação - Mestrado e Doutorado em Educação Física da Universidade Católica de Brasília.
} 
to the relationship experiences with other people and the world. Another relevant aspect was the possibility to get to know a completely different environment and specially experience diverse feelings such as fear, risks, ease and peace. This experience allows moments of introspection, contemplation and silence, but also solidarity, sociability and awareness of environment preservation needs.

KEYWORDS: Leisure Activities. Sports. Nature.

\section{INTRODUÇÃOO}

Experimentadas e entendidas de várias maneiras ao longo da história, as atividades corporais junto à natureza recentemente têm recebido diferentes nomenclaturas que envolvem as atividades físicas e de lazer nesses espaços, denominando-as de AFANs - Atividades Físicas de Aventura na Natureza (BETRÁN, 2003); Esportes Radicais (FERNANDES, 1998; UVINHA, 2001) ou Esportes de Aventura (COSTA, 2000; BRUHNS, 2003; MARINHO, 2003; UVINHA, 2005).

As atividades que englobam esta temática, independente da nomenclatura adotada, podem ser classificadas em conformidade com o ambiente onde são realizados - meios terrestres (montanhismo, mountain bike, camping, corrida de orientação, moto cross, skate, trekking, caving), meio aéreo (balonismo, pára-quedismo, vôo livre, asa delta, bad jump, tiroleza) e meio aquático (bóia cross, rafting, caiaque, canoagem, mergulho, surf) -, estando sua oferta relacionada a diversos fatores, dentre eles, as características regionais e os recursos naturais disponíveis. A relação das características regionais com os diferentes tipos de atividades na natureza pode ser exemplificada com as assertivas de Pimentel e Saito (2010), quando relatam que a prática do balonismo é bastante recorrente na região de Maringá - PR devido à ausência de morros e florestas extensas na estrutura natural.

Em relação à sua adesão, nos últimos anos, as atividades na natureza têm apresentado um crescente aumento (BRUHNS, 1997), podendo esta condição ser 
observada no Brasil por intermédio dos dados apresentados pelo Atlas de Esporte, que em 2006 sinalizou a existência de 8.276.118 praticantes de esportes de aventura (água, terra, ar, inverno e mar) registrados, sendo 145.998 regulares e 8.130 .120 ocasionais (DACOSTA, 2006).

Dentre os motivos que tem levado às pessoas a se envolverem com as atividades na natureza podem ser citadas a evasão das atividades rotineiras e estressantes para atividades relaxantes, que segundo estudiosos da área, dentre eles Bruhns (1997; 1999; 2003), Fernandes (1998), Camacho (1999), Lacruz e Perich (2000), Marinho (2001; 2003), Tahara e Schwartz (2003), Betrán (2003), Uvinha (2003; 2005), Bahia e Sampaio (2005) e Sampaio (2010), tem ocorrido em função da crise social que o ser humano vive atualmente e o seu desejo de romper com o cotidiano, principalmente vinculado aos grandes centros urbanos.

Essa condição tem sido observada nas mais diferentes faixas etárias, pois "os adultos têm utilizado tais práticas para sair da rotina e combater o estresse, jovens estão à procura de atividades que proporcionem mais adrenalina e as crianças praticam tais atividades para sair da monotonia e a falta de espaços abertos" (PEREIRA; PIMENTEL; LARA, 2004, p. 112).

Outro fator que tem levado as pessoas a procurar atividades esportivas e de lazer na natureza é a busca de reconciliação do ser humano com a natureza (BAHIA; SAMPAIO, 2005; UVINHA, 2005; SAMPAIO, 2010), haja vista que as práticas corporais na natureza podem agir como via de re-significação da relação ser humanonatureza, os reaproximando e sensibilizando, havendo possibilidades, ainda, de que, com isso, ocorram contribuições para com a minimização dos impactos ecológicos (SILVA; FREITAS, 2010). 
Sobre esta questão, Sampaio (2010) nos lembra que:

[...] somos não apenas parte do todo, mas somos um todo e este em nós. Da terra que somos moldados, ao molde que dela fazemos, estamos impregnados de interdependência. Não se trata de oposição, mas de relação. As distinções precisam ser organizadas à luz de uma percepção relacional e interdependente, o que exige uma pronta mudança de concepção antropológica. A percepção de centralidade do humano sobre o ecossistema precisa dar lugar a uma concepção de relações de mútuas interdependências, sem que isto desqualifique o ser humano, mas o re-signifique na relação de perceber-se como parte necessária e com necessidades de toda a complexa e múltipla diversidade do que existe (p. 90).

Desta forma, as atividades na natureza têm sido buscadas com o intuito de enfrentar o desconhecido, de se ter maior intimidade com a natureza, seus mistérios e belezas originárias, um encontro consigo mesmo e a possibilidade de "ler" o mundo por meio de outros sentidos, superando a racionalidade como única e prioritária forma de conhecimento.

É neste sentido que as cavernas, um espaço natural, formadas em decorrência de fenômenos naturais, originárias de regiões calcárias, configuradas por cavidades subterrâneas, posteriormente apropriadas pelo ser humano (MELO; FARIA, 2007), conhecida também como "gruta e lapa" nas regiões Sudeste e Nordeste e "lapa" no Norte de Minas Gerais, configuram-se num importante equipamento natural de atividade física e de lazer, que pode contribuir com a aproximação humano-natureza, sobretudo por intermédio da vivência do caving.

Segundo Auller, Brandi e Rubbioli (2001) e Marra (2001), a relação do ser humano com as cavernas remonta a muitos séculos ou milênios de sua história, estando assim, por diversos motivos, em intima relação com as cavernas, ora como moradia, ora como lugar de culto e adoração, ora refugiando-se no seu interior. 
Nesse sentido, encontramo-nos com um espaço que pode se transformar em ambiente propício para atividades de lazer na natureza, sendo necessário inserir no cenário a reflexão e os processos organizados de proteção, de preservação da natureza e sustentabilidade para que, de fato, representem qualidade de vida não apenas aos praticantes, mas ao ecossistema como um todo.

Proveniente do grego, spelion (cavernas) e logos (conhecimento), a espeleologia surge com a principal finalidade de promover o estudo, a observação e a exploração das cavernas, objetivando a criação de efetivos mecanismos que contribuam para a sua compreensão e conservação (MELO; FARIA, 2007). Enquanto disciplina de estudo, a espeleologia ao ocupar-se do estudo da gênese, evolução e povoamento biológico dos ambientes de caverna, permitiu a criação de técnicas apropriadas para desenvolver sua exploração visando tanto o conhecimento científico quanto a derivação para a espeleologia como técnica esportiva, entendida como a prática do caving. Esta prática hoje pode ser vista tanto na experiência de pessoas amantes de atividades físicas e esportes de aventura na natureza, quanto pelos nichos de mercado voltados ao turismo de aventura na natureza, um fator que chama a atenção para uma postura crítico-criativa no estímulo a esta atividade na natureza. E, ainda,

[...] do ponto de vista esportivo uma diferença básica distingue a espeleologia de outros esportes congêneres: nela não se privilegia a competição entre os indivíduos ou grupos, ao contrário, exige a solidariedade e o trabalho de equipe. Não se trata, igualmente, de vencer a natureza, mas suplantar-se a si mesmo, suplantando limites físicos, técnicos e de conhecimento (LINO, 1989, p. 45).

Muitos autores corroboram com esse ponto de vista ao apresentar sua concepção de caving como atividade que não visa à competição, o desafio, ou, muito menos, o vencer a natureza, mas sim o trabalho em equipe, objetivando o estudo, a observação, a documentação e a contemplação das cavernas. Conforme afirma Munster (2004, p. 
145), a atividade de aventura na natureza configura-se "como uma prática esportiva derivada da espeleologia, consiste na visitação de cavidades naturais para desfrute pessoal ou coletivo, onde prevalece o espírito de interação com o grupo e com o meio natural".

Na visão de Larsen (2007), o caving consiste em descer abismos, explorar fendas estreitas, rastejar por condutos apertados e nadar em rios subterrâneos, procurando descobrir novas galerias e salões. Já para Bueno (2007), o caving pode ser entendido como uma atividade direcionada para a área técnico-esportiva, sendo uma mutação da área científica que busca a prospecção e exploração de cavernas, por meio da documentação, da fotografia e da logística. É uma mistura entre ciência e esporte de ação. A atividade une a exploração de cavernas, sua pesquisa, documentação e conservação, com as técnicas usadas para seu estudo - mergulho e rapel.

No Brasil, essa atividade junto à natureza tem sido praticada com finalidades esportivas ou de lazer, sendo marcada por uma procura significativa na perspectiva de aventura na natureza por pessoas de diferentes faixas etárias. Contudo, verifica-se, na literatura, a existência de poucos estudos sobre o caving, assim como os existentes têm se limitado à análise de atividades pontuais, como a relação entre a espeleologia e o esporte.

Dessa forma, a presente investigação buscou analisar as possíveis contribuições do caving na experiência de relações humanas e ecossistêmicas como atividade de aventura e lazer na natureza para os integrantes do Espeleogrupo Peter Lund-EPL. 


\section{PROCEDIMENTOS METODOLÓGICOS}

Este estudo foi realizado por meio de uma combinação de pesquisa bibliográfica e de pesquisa de campo. A opção por uma abordagem qualitativa buscou coerência com o objeto de pesquisa ao considerar a importância de selecionar procedimentos capazes de captar de forma sistemática a descrição e explicação de fenômenos (RICHARDSON, 1999).

Nesse sentido, recorreu-se às entrevistas semi-estruturadas (GIL, 1991) como técnica de investigação, realizada durante as práticas de caving planejadas pelo grupo estudado "Espeleogrupo Peter Lund - EPL”, de Montes Claros - MG.

A área escolhida para a coleta de dados associou a presença de um grupo praticante do caving e as características da localidade de Montes Claros - MG e na região norte-mineira, por ser um município e região de geomorfologia cárstica, onde a prática deste esporte é favorecida pela existência de Lapas e de sítios arqueológicos, destacando-se o Parque Estadual Lapa Grande. As áreas em que se desenvolveram a pesquisa foram a Lapa Grande; a Lapa D’água; a Lapa Pintada; a Lapa Claudina; a Lapa da Santa e o Vale do Peruaçuzinho.

A escolha da amostra para a realização deste estudo deu-se de forma intencional e levou em conta critérios de representatividade e acessibilidade (GIL, 1991), sendo o grupo pesquisado composto por dez adeptos profissionais da modalidade, sendo nove do sexo masculino e uma do sexo feminino, com faixa etária de 32 a 50 anos, pertencentes às classes econômicas A e B, residentes em Montes Claros, MG e integrantes do grupo Espeleogrupo Peter Lund - EPL.

O tratamento dos resultados das entrevistas semi-estruturadas, após processo de transcrição, foi realizado por meio de um agrupamento das respostas, organizadas em 
categorias, dada a reincidência observada. As categorias selecionadas para esta análise

foram: 1). significado da caverna e do caving para os praticantes; 2). benefícios do caving como atividade física e de lazer; 3). emoções presentes na prática do caving; 4). relação ser humano/caverna; 5). sentidos corporais presentes na vivência do caving.

\section{RESULTADOS E DISCUSSÃO}

$\mathrm{Na}$ análise dos resultados, da primeira categoria (significados e sentidos da caverna e do caving), os dados indicam que os participantes da amostra atribuem à caverna sentidos desejados e não encontrados em seu cotidiano do dia-a-dia, destacando, dentre eles, paz, tranquilidade, descanso, encontro pessoal, espontaneidade, harmonia e sociabilidade.

Um dos praticantes afirmou que, quem visita uma caverna,

[...] encontra a paz, eu desloco do mundo dessa correria que a gente tem aqui fora. Eu não sei se seria introspecção em relação às minhas vidas passadas (...). Lá eu fico mais tranquilo, relaxo, eu viajo ali dentro. Eu imagino um monte de coisas relacionado com as rochas. Como aquilo tudo se formou e a gente acaba descansando a cabeça das coisas que acontece aqui fora, dessa correria louca, desse mundo atual nosso. Seria esse momento de me encontrar, de paz mesmo, de tranquilidade, de ter a possibilidade de parar para pensar nas coisas que são necessárias para a minha vida aqui fora; para as coisas que eu gosto realmente, que é ficar dentro de uma caverna, sentir o clima lá dentro, sentir a própria rocha, como a gente diz, conversar com os colegas de forma bem tranquila, sem estar naquela exigência de falar uma coisa certinha, sem estar buscando coisas relacionadas com a profissão, com o dia-a-dia (sujeito 7).

Outro depoimento é o do sujeito 8, que reitera a percepção da caverna como lugar de paz, de tranquilidade absoluta, acrescentando outras possibilidades de sentido, como a de ambiente de ausência de som e luz, de introspecção, de meditação, de aventura, de mistério, de magia, de beleza, de sensações, muito diferente do mundo urbano: 
[...] um lugar onde reina tranquilidade absoluta. Não tem luz, não tem barulho. A luz e o barulho é você quem leva (...). É um ambiente de introspecção. A gente pode buscar meditação, pode buscar a tranquilidade mesmo. E, por outro lado, também são várias facetas. Tem esse lado mais de introspecção. Tem o lado de aventura e tem o lado de mistério. A sensação de estar em um lugar que ninguém nunca foi é muito bacana e a beleza também que é fantástica. Ambiente mágico devido às belezas cênicas, sensação de paz, de tranquilidade e de silêncio. Estar em um lugar diferente de tudo é um mistério. É difícil de falar. São muitas sensações. Para você definir uma caverna no sentimento é muito mais complicado. Representa, para mim, um lugar diferente de tudo que tem aqui fora. É outro mundo. A gente não define caverna, a gente sente. Só estando lá para sentir, não dá para falar (sujeito 8).

Chama a atenção, a perspectiva de buscar uma nova linguagem para dizer da experiência de estar em profunda relação com a caverna. A linguagem racional não ajuda daí a necessidade de sair do âmbito da pergunta sobre como você define caverna, para indicar que a linguagem possível é como você "sente" a caverna. Trata-se de permitir a experiência em outras dimensões. O ritmo é outro, não o da correria urbana, mas o do silêncio e das belezas e mistérios que vão se apresentando a cada novo passo em direção ao fundo da caverna.

A introspecção é ressaltada por ambos como uma possibilidade encontrada nesse ambiente e está experimentada não como angústia, mas como espaço prazeroso de estar consigo e com os outros, longe de regras fixas que pré-definem os comportamentos esperados das pessoas.

À vontade do ser humano, de romper com o cotidiano estressante usufruindo maior tranquilidade e paz, desencadeia sua aproximação das atividades físicas de aventura na natureza com o intuito de conquistar uma vida mais tranquila e prazerosa, contrária à vivenciada no dia-a-dia, evadindo-se, assim, das tensões que afetam os estados emocionais do ser humano atualmente (LACRUZ; PERICH, 2000). Com isso, o interesse pela prática do caving traz para o cenário contemporâneo a necessidade de 
realizar processos de interrupção do cotidiano urbano agitado e penetrar em um mundo ainda novo para os seus praticantes. Contudo, sem cair em uma visão funcionalista de tornar esta atividade uma válvula de escape e sim um aprendizado de novas possibilidades de relação ser humano e ecossistema.

O ambiente marcado pela observação do silêncio e da escuridão, como mediadores importantes para as necessidades humanas fundamentais de descanso, de meditação, de tranquilidade para refletir sobre a vida e o que se deseja para ela, podem propiciar a integração humano-ecossistema, com potencial de re-significar as relações, promovendo um desenvolvimento pessoal, social e ecossistêmico muito significativo. Portanto,

[...] estar em uma caverna é como se a pessoa entrasse em um estado de meditação, sem necessidade de se concentrar para isso, porque o próprio ambiente já proporciona isso ao visitante. A caverna permite um contato mais consciente e significativo do visitante com a natureza, consigo mesmo e com os outros, possibilitando aquisições de novas atitudes e de valores para a melhoria da qualidade de vida de quem visita uma caverna (sujeito 8).

No ambiente de caverna, a sociabilidade, outro significado atribuído por um dos praticantes do caving, pode ser entendida como solidariedade, como relações sociais e relação de laços afetivos entre os seres humanos e, destes, para com a natureza, ou seja, uma reaproximação do ser humano com o ecossistema, que também exige uma maior interdependência entre os agentes envolvidos em sua prática, conforme fica evidenciado em outro depoimento.

[...] a caverna representa harmonia, representa convívio e boas relações com o universo ambiental, tendo em vista que, na natureza, quando a gente compartilha com outros colegas essa vivência, existe uma relação de interdependência um do outro para com o meio, ou a gente não consegue realizar as atividades. Então, existe toda uma sinergia, uma sintonia entre ser humano e natureza, ser humano/ser humano, tentando perceber e abstrair os pontos que a gente acha que é harmonioso dentro da natureza. Eu penso que quanto mais eu doar para a natureza, mais eu recebo nessa relação de percepção, de 
harmonia, de interesse. [...] A gente entende que essa relação, ela é muito apurada [...], porque as relações são inúmeras até que a gente venha a descobrir (Sujeito 1).

Para Candido (2001), a dimensão de sociabilidade organiza a formação de uma rede ampla de relações, contribuindo para uma unidade estrutural de um grupo e está intrinsecamente ligado às relações sociais cotidianas. Em conformidade com o autor, a sociabilidade em um ambiente de caverna pode ser entendida como uma forma de solidariedade, percebida como necessidade de ajuda mútua que todas as pessoas têm. Assim,

[...] a caverna é um espaço de sociabilidade, porque eu sou um grande admirador da geografia ambientalista e me considero um ambientalista também não tão romântico, mas desbravador de um pragmatismo que está aí para ser descoberto dentro dessa ideia ambientalista. Mas eu descobri aí uma pessoalidade, uma visão minha mesmo de que a caverna é um espaço de sociabilidade, porque foi isso que vivi lá, foi que senti, reconheci e acabei pactuando com outras pessoas que tiveram a mesma sensibilidade, talvez o mesmo sentimento de que a caverna era um grande espaço de sociabilidade. Na medida em que a gente debatia sobre os primórdios e a história espeleo-paleontológica, arqueologia e começava ter contato visual com as pinturas rupestres também, aquilo parece que ia aproximando a caverna como um espaço de sociabilidade. Eu acho que a sociabilidade durante a prática do caving vai depender das individualidades, das personalidades. Cada um vai ter uma leitura diferenciada desse ambiente e talvez essa pluralidade de interesses, de personalidades, de intelectualidades e desconhecimento fazem tornar a caverna um espaço de sociabilidade interessantíssimo (Sujeito 4).

O que caracteriza a sociabilidade, segundo Magnani (1996), são as experiências humanas de interações sociais, nas quais as pessoas cultivam estilos particulares de entretenimento, mantêm vínculos de sociabilidade e de relacionamento, criando modos e padrões culturais diferenciados. Ou, na percepção de Sampaio (2010), de que a maior proximidade entre as pessoas envolvidas em uma atividade torna mais intensa a sociabilidade, promovendo mecanismos de comunicação de novas percepções do mundo e das relações. 
Em relação à segunda categoria (benefícios do caving como atividade física e de lazer), os integrantes do Espeleogrupo Peter Lund consideram a experiência como aquela que provoca "um cansaço bom", marcada por intervalos de descanso e de avanço, traz mais disposição, mais preparo físico, maior dinâmica, revigoramento, integridade das dimensões do ser humano, conforme pode ser observado por meio dos depoimentos a seguir:

[...] lá dentro, a gente fala que é um cansaço gostoso, porque você fica com a respiração ofegante. Às vezes, você faz um esforço além da sua capacidade, se cansa muito mais. Três, dois minutos, você dá uma parada para conversar sobre alguma coisa. Acaba descansando. Então, por isso, eu acho que a gente não acaba percebendo esse cansaço. A gente pára muito. Tem muitos intervalos entre um caminhar e outro dentro da caverna (Sujeito 7).

Eu falo para várias pessoas. Eu posso fazer qualquer tipo de atividade nos finais de semana, planejamento de aula. Eu fico extremamente cansado na segunda-feira, mas se o meu final de semana foi cavernar [caving], eu posso ter feito o maior esforço do mundo, na segundafeira, eu estou uma pessoa extremamente disposta a qualquer tipo de atividade. É como se lavasse a alma. Então, o ambiente cavernícola, dentro de uma caverna, ela dá essa energia, a paz interior, por você está se deleitando nas belezas do interior do universo, da terra. Eu acho que é isso [...] você fica mais disposto. Quando se pratica o caving, você adquire um preparo físico de certa forma que vai melhorar o seu dia-dia. Seu cotidiano para você está mais disposto, mais dinâmico (Sujeito 3).

O bem-estar corporal nesse tipo de atividade é bem marcante. Parece que o corpo fica revigorado, a gente cansa, mas o cansaço é bom. Parece que a caverna tem uma força oculta de promover esse bemestar corporal, porque se fosse um outro tipo de atividade qualquer, após a sua prática, o corpo estaria cansado. A caverna tem essa capacidade de energizar todo o nosso corpo, principalmente a nossa cabeça. Acho isso bacana. Acho que todos deveriam conhecer uma caverna (Sujeito 6).

Bruhns (2003), em sua reflexão sobre a prática de aventura na natureza, atribui ao contato direto com a flora, a fauna, as alturas, as amplitudes e a outros aspectos peculiares o efeito catártico que "produz leveza" gerando bem-estar e alegria como 
parte integrante da própria experiência. E o bem-estar proporcionado pela aventura do caving é demonstrado no depoimento que segue:

[...] o corpo é muito pleno, não só em termos de exercício mesmo, mas também da própria cabeça. Psicologicamente, tá trabalhando ali também. A atenção, o cuidado, a concentração e o deslumbramento. Então, o corpo ali é pleno. Mente, músculo, sangue, enfim todo o corpo é pleno muito bem dentro de uma caverna [...]. É um exercício forte, pesado às vezes, até mais gratificante. Quando você sai de uma caverna, como diz a minha irmã, "é um cansaço bom", porque você trabalha o organismo e tem aquela sensação de prazer que o exercício físico proporciona e, além de tudo, você desestressa ali. Você trabalhou a cabeça e sua cabeça está mais tranquila. Você sente cansaço físico, mas é um cansaço bom. É prazeroso (Sujeito 8).

Há um consenso nos depoimentos sobre os benefícios proporcionados pela prática do caving. A plenitude de uma percepção integral de ser humano no mundo é marcante. Nas reflexões de seus praticantes todos os sentidos do corpo são aguçados e permitem dissipar as tensões experimentadas no cotidiano e fazer uma experiência de introspecção muito significativa, resgatando a gratuidade do viver de forma intensa. Elementos importantes como a atenção, a concentração, a contemplação, o cuidado de si e do outro são intensamente vivenciados no desafio de adentrar as belezas e os mistérios das cavernas.

Entrar e sair das cavernas são experiências distintas e nem todas previsíveis. A preparação para a entrada envolve toda uma dinâmica de tomar ciência dos equipamentos de segurança, dos percursos delineados, das dificuldades básicas que serão encontradas, contudo, integrar-se ao ambiente da caverna promove as mais distintas experiências abrindo novos horizontes em vista de uma releitura da sociedade, suas minúcias, seus detalhes, parcelas importantes que nos tornam mais humanos e responsáveis uns com os outros e com o ecossistema que nos abriga. 
Desta forma, observa-se que a relação da experiência em caverna também está associada a um tempo e espaço de lazer, como uma procura constante de maior qualidade de vida no âmbito individual e coletivo (CARVALHO, 2005), a exemplo do observado em estudo realizado por Garcia, Kowalski e Alves (2009), em Viçosa - MG. Outros estudos também indicam que investimentos em vivências de lazer junto à natureza estão relacionadas à busca da melhoria da própria qualidade existencial (TAHARA; SCHWARTZ, 2003).

Moraes e Oliveira (2006) admitem que os esportes na natureza proporcionam sensações, emoções e percepções bastante diversas das presentes no cotidiano, possibilitando dar vazão às angústias, aos medos, aos preconceitos desenvolvidos cultural e socialmente. Para os integrantes do EPL, o lazer em ambiente de caverna, por meio da prática do caving, é considerado uma atividade prazerosa, com potencial de reorganizar as próprias experiências de vida.

Na terceira categoria (emoções presentes na prática do caving), os depoimentos indicaram relação com a busca de lazer e emoção, em função da aventura, do risco, da novidade, do desconhecido e do confinamento temporário, intercalando sensações de medo, de prazer, de beleza, de descoberta, entre outras.

Na verdade, a caverna é um lugar habitado, lugar para se habitar vida, lugar de ciência, lugar de lazer, lugar de cultura. A caverna é um lugar de sacralização de ideias. É um lugar de sociabilidade. É um lugar de confraternização mesmo. A caverna é o lugar do homem. A caverna é um lugar de magia. É um lugar de magia interessante. A caverna é um lugar mágico, porque os olhos das pessoas brilham no escuro como agulhas de Gipsitas. Eles ficam meio fascinados, eles ficam meio assustados, principalmente quando se apagam as luzes dentro da caverna. Eles ficam extasiados (Sujeito 4).

Moraes e Oliveira (2006), em seu estudo sobre emoções em situações de risco no alpinismo de alto nível, constataram que o alpinismo é um esporte que proporciona 
uma gama de emoções e de elevada intensidade. Esses autores admitem que os elementos encontrados na emoção são: medo, raiva, ansiedade e preocupação, sensações de liberdade, poder, prazer, superação, vitória, auto-realização, recompensa pelo esforço e solidariedade. Para esses autores, os enfrentamentos de desafios que ocorrem na escalada é que definem a emoção de chegar ao cume. Algo semelhante se observa nos relatos dos praticantes de caving.

Toda nova experiência é realmente única. [...] fiquei com medo. Eu nunca tive medo [...], o chão fez ruir [...] tal era o volume de água, [...] cada vez que a gente chega à caverna, modifica tudo, a sua percepção tá um pouquinho mais refinada, a caverna tá mais madura [...]. A cada pessoa que soma, você percebe como ela interage [...]. É uma história bonita, a gente poderia considerar um ser vivente. [...] nós somos como célula desse ser. A caverna me deixa muito excitado, de alguma forma. Então vêm estas questões da excitação, um pouco de medo e prazer. Tudo é multifacetado. É uma "emoção multifacetada" [...] (sujeito 10).

A presença das sensações e das emoções no caving é perceptível nos depoimentos: uma profunda associação entre o êxtase buscado e o que se experimenta. Interessante é a compreensão de que medo e prazer são facetas da experiência humana e podem ser vividas de modo agradável e prazerosa ou não. Ao descrever sua emoção como multifacetada, o integrante do EPL assume o paradoxo do medo e do prazer ao dividir o mesmo espaço, sem que uma emoção anule a outra. $\mathrm{O}$ mesmo se observa na expressão de outro praticante, ao dizer que,

[...] No início, é medo, enquanto você não conhece. Quando você começa frequentar uma caverna, você tem a sensação de medo, mas, ao mesmo tempo, tem essa sensação de vontade de conhecer aquilo que é diferente e esse mistério que envolve o ambiente cavernícola. Depois o prazer de tá ali [caverna] é renovador. Depois que você visita uma caverna, você se recicla mesmo. A energia sua é diferente. Você fica mais tranquilo. Você se desestressa. Então essa sensação de tranquilidade, ela vem com o tempo na verdade, porque no início, a sensação de aventura é maior. Ela acaba sobrepondo, você não consegue perceber esse outro lado mais tranquilo da caverna (sujeito $8)$. 
Há nos depoimentos uma tentativa de estabelecer relações desta com outras práticas de aventura na natureza, mas a gama de emoções relatadas indica uma singularidade própria que é absorvida por quem pratica e para quem, não poucas vezes, falta a linguagem capaz de descrever a experiência e os sentimentos instados em toda a sua amplitude, conforme se observa na relação que um deles faz entre montanhismo e caving:

As sensações do corpo diante desse tipo de ambiente são muito parecidas com o montanhismo. Entretanto, o escuro, o isolamento e o confinamento possibilitam outra relação com o corpo e suas reações instintivas e treinadas. Em todos os momentos e, nas situações de estresse provocadas pelo risco, todos os sentidos são solicitados. O desconhecido, o perigo e a ânsia da descoberta criam um turbilhão de sensações e emoções. No dia a dia, isso significa profundas mudanças na vida e no cotidiano dos praticantes. Essas mudanças, sempre positivas, não são percebidas pela maioria das pessoas. A proximidade com o desconhecido e com os riscos aguçam os sentidos, tornando o praticante uma pessoa mais forte, moldada pela natureza, pelo instinto ágil e pelo raciocínio lógico. A emoção no montanhismo é diferente da espeleologia (caving). A emoção no ambiente de caverna está associada à beleza do ambiente cavernícola, por meio de suas formações. Já no montanhismo, a emoção está relacionada ao risco, aos obstáculos a ser ultrapassados. No montanhismo, a atividade, ela depende principalmente de quem está praticando. Então, o risco é maior (Sujeito 2).

Moraes e Oliveira (2006) afirmam ser mais possível experimentar e sentir as emoções do que entendê-las e descrevê-las. Nos depoimentos pode-se destacar a ênfase dada à ocorrência de emoções, com significado positivo. O elemento emocional bastante enfatizado pelos integrantes caracteriza o prazer, associado ao belo, ao risco, à aventura, ao medo, ao perigo, aos obstáculos, ao desconhecido, ao bem-estar corporal e a tranquilidade, durante a prática do caving, demarcando tal prática como beneficio pessoal e coletivo para os seus adeptos.

A quarta categoria tratou de identificar as relações que se estabelecem entre ser humano e caverna, por meio da prática do caving. Entre essas, pode se destacar a 
relação de respeito à natureza e de defesa do meio ambiente, como se percebe no depoimento a seguir:

[...] Então, a minha relação de defesa do meio ambiente surgiu com a prática da espeleologia e do cavernar [caving]. No momento em que eu estou fazendo uma visita numa caverna é um momento místico para mim. É uma oração. [...] eu estou mais próximo de Deus. Eu procuro tá mais em silêncio, mais contemplativa mesmo, para buscar esse contato mais próximo, porque, se não, você perde essa oportunidade de tá relacionando com a natureza, não simplesmente por estar ali, porque é um lugar diferente. Ali as coisas estão equilibradas, pelo menos mais equilibradas que na cidade. Quando você está em um ambiente desse, você tem condição de estar equilibrado também (Sujeito 8).

Nota-se nesse depoimento que o cuidado e preservação ambiental aparecem associados, não em um primeiro momento, há um discurso sobre a importância de preservação ambiental, mas a percepção de que há um equilíbrio distinto ali que é importante no processo de auto-recomposição para o cotidiano urbano com suas outras exigências. A experiência do silêncio é retomada, assim como o processo de contemplação, meditação, introspecção que, por vezes, é mencionado como momento mágico, místico ou com traços de religiosidade.

Percebe-se, com isso, que o processo de harmonia experimentado de forma individual ou coletiva é parte das expressões acerca do significado de caverna na experiência de quem pratica esta interação por meio do contato direto com a natureza através do caving. Uma nova percepção sobre o estilo de vida, determinada por posturas éticas, morais, sobretudo relacionadas à questão da vivência do tempo e espaço de lazer pode ser observada, redimensionando a perspectiva de que as atividades na natureza precisam estar abertas para um aprendizado novo - que é o do respeito e cuidado com o meio ambiente - ainda muito desconhecido numa relação que se 
pretende interdependente e não exploratória ou depredatória como a que se experimenta há séculos na história humana ocidental.

Bruhns (2003), ao tecer considerações a respeito do significado das sensações e emoções relacionadas às atividades de aventura na natureza, admite a possibilidade de formação de um novo estilo de vida, caracterizado pela adoção de novos valores e hábitos na forma de viver e perceber a importância da natureza resultando na melhoria da qualidade de vida. Sobre esta questão, Silva e Freitas (2010, p. 225) argumentam que "reflexões sobre a vida e sobre si mesmo, desenvolvem nos sujeitos que usufruem as práticas corporais na natureza um sentido mais íntimo, envolvendo uma reaproximação do homem com a natureza, despertando o homem como ser inserido no cosmo".

Outra descoberta importante ao analisar o resultado da relação ser humano e natureza é a perspectiva de religiosidade encontrada em alguns depoimentos dos integrantes do Espeleogrupo Peter Lund (EPL):

A caverna é um lugar de êxtase também. [...] Ela é natural, talvez ela seja natural ao extremo, a ponto de se fazer quem entrar dentro dela enxergar a sua própria naturalidade. [...] O papel da caverna na formação do ser humano é uma coisa mágica mesmo. Só indo para perceber isso. É um ambiente de paz. É um ambiente de reflexão, um ambiente de transformação humanística, de valorização cultural, valorização histórica, de percepção da vida, de conhecimento cientifico in natura, de pragmatismo, de socialização, de troca de experiência, de fluxo e troca de energias, de valorização ambiental e de conhecimento da nossa própria natureza [...] Ambiente de reflexão, religiosidade, misticismo, espiritualidade. Acho que é um bom lugar para refletir sobre a vida, um bom lugar para se refletir sobre nós mesmos (Sujeito 4).

A visita à caverna, para alguns integrantes, configura-se numa espécie de ritual religioso, místico, que põe em sintonia o humano e o divino, principalmente no que concerne ao mistério e à contemplação, conforme observado nos depoimentos dos sujeitos 8 e 4, que testemunham um estado de introspecção e harmonia, próprio das 
cavernas e vivenciado em poucos momentos e lugares, o que aponta para um diferencial dessa prática que traz a dimensão da religiosidade na perspectiva de qualidade de vida, conforme concebida por Ferrans e Powers (1993).

Nota-se que não se trata de uma expressão de culto referenciada a uma determinada religião, mas uma expressão de ritos que fazem parte da existência humana desde os tempos primitivos e estão relacionados aos valores e crenças de determinadas pessoas dentro de um marco histórico e cultural que lhes é pertinente (BENOIST, 1977). Os ritos expressam os valores existenciais, segundo os quais as pessoas organizam seu olhar para o mundo, e o ambiente cavernícola pode representar a possibilidade de um encontro mais profundo do ser humano com a sua própria existência e com os mistérios que a transcendem.

Em relação à quinta categoria referindo-se aos sentidos corporais presentes na vivência do caving, os resultados encontrados mostram uma necessária e constante utilização dos sentidos sensoriais importantes e fundamentais na primeira infância e depois abandonados quando da inclusão da racionalidade operacional como suficiente para a experiência humana de conhecer o mundo. $\mathrm{Na}$ experiência dos praticantes do caving ocorre um processo de resgate dos sentidos corporais com grande intensidade e qualidade.

É um ganho interessante de todos os sentidos. Eles passam a ficar em alerta devido à escuridão. [...] $\mathrm{O}$ tato, a gente, é aquela história. $\mathrm{O}$ contato com as rochas, com as formações, a orientação que a gente procura trabalhar com as pessoas que visitam a caverna, justamente as questões das formações. Elas não podem ser tocadas. Isso gera um impacto. Muitas vezes quebram, acontece de quebrar um espeleotema, acontece de quebrar um espeleotema muito grande, mas com a rocha esse contato é muito interessante, sim. O olfato é em função das ocorrências que a gente consegue perceber isso muito claramente. Quando você aproxima do ambiente habitado por morcego, principalmente em função do guano, que libera um odor, facilmente é perceptível. A visão passa a ter um papel fundamental nessa história toda, mas não é a condição básica para a visitação na caverna. A gente 
poderia imaginar que pessoas com deficiência visual poderiam perfeitamente visitar caverna com orientação devida e tá observando de forma diferente. O próprio tato ajudaria nisso. Então a visão, ela não é uma condição essencial para se visitar uma caverna não, mas ela acaba gerando fascínio com as formações espeleotemáticas que podem ser tocadas. Eu acho que, na verdade, são múltiplas percepções que acabam sendo desencadeadas, passíveis de até gerar uma confusão mental. É muita coisa para se observar. É muita atenção para se dispersar, muito cuidado precisa ter. Então, é como os escoteiros sempre em alerta. Então as múltiplas percepções, elas fluem na caverna, tem "n" situações. Eu não saberia elencar todas aqui. Cada caverna é uma situação diferente. Cada passo dado dentro de uma caverna é uma situação diferente. Então, a cada passo dado, é uma nova percepção, é uma nova demanda [...] (Sujeito 4).

Ao analisar esse depoimento sobre os sentidos corporais, percebe-se uma aproximação entre esses resultados e os encontrados por Munster (2002) em estudo sobre as manifestações emergentes a partir das relações corpo e natureza durante visitas às cavernas do Parque Estadual Turístico do Alto Ribeira - PETAR, com pessoas com deficiência visual e/ou pouca visão. A autora demonstra que a incursão em ambientes naturais pode consistir em um elemento importante no processo de descoberta do próprio corpo e da natureza, favorecendo as pessoas com deficiência visual a exploração do seu potencial sensorial, com mais intensidade e qualidade. Esse resultado apresenta a importância de se considerar atividades físicas e de lazer na natureza como potenciais propulsores tanto do surgimento quanto do resgate dos sentidos corporais importantes para a experiência de ser e estar no mundo.

$\mathrm{Na}$ aventura, é o resgate da percepção do tato, olfato, visão e outros. Sentidos que são pouco lembrados ou percebidos em nosso cotidiano, tornam aguçados dentro de nós. Lá [na caverna], você sente e se sente de forma diferente. $\mathrm{O}$ cardíaco chega ao limite extremo, o sangue pulsa nas veias que marcam a pele suada e às vezes fria. Os lábios molhados pela água do cantil, logo estão secos e a garganta arranha sem falar. A tão falada adrenalina te toma. $\mathrm{O}$ tremor pelo medo e o cansaço às vezes é inevitável. Sua respiração acelera e desacelera tão rápido quanto um raio e você não consegue entender e controlar. É na aventura que seu espírito de consciência amplia (Sujeito 1). 
O estudo de Bruhns (1997) corrobora com as discussões sobre os sentidos corporais, pois, segundo a autora, entendimentos, sentimentos e sentidos se manifestam paralelamente no corpo humano, interagindo com a natureza. Bruhns (2003), em outro estudo, argumenta que, nos esportes de aventura, há uma busca literal de mergulhar na natureza, onde uma emoção "à flor-da-pele" pode ser experimentada como aventura imaginada ou captada por meio de todos os poros, da absorção do impacto visual, permitindo uma sensação de corpo inteiro. Destaca ainda que o exercício dos sentidos, como ver, ouvir, tocar, cheirar ou degustar sons, cores, superfícies, cheiros ou sabores faz parte de um conjunto intenso em que a tatilidade agora é representada pelo corpo como um todo, o qual "toca a natureza" e é por ela tocado. A pele não mais separa ser humano e natureza, não há limite, a fronteira não passa de uma superfície porosa de troca entre o que capta e o que extravasa.

Assim, os sentidos corporais estão muito presentes no caving e, a partir dessa prática, é possível pensar novas formas de perceber o corpo, a natureza e as relações de alteridade.

\section{CONSIDERAÇÕES FINAIS}

Neste estudo, buscou-se analisar as possíveis contribuições do caving na experiência de relações humanas e ecossistêmicas como atividade de aventura e lazer na natureza para os integrantes do Espeleogrupo Peter Lund-EPL e os desdobramentos que podem orientar outras pessoas que se envolvam em tal prática.

A respeito das relações estabelecidas entre o ser humano e a caverna, os depoimentos demonstraram que o contato com o desconhecido é muito intenso e proporciona conhecimentos novos em relação à natureza, faz aflorar a consciência de 
preservação, como oportuniza uma experiência muito distinta do cotidiano. Não no sentido de fortalecer uma visão funcionalista do lazer, cabe ressaltar que a experiência narrada pelos praticantes está marcada pelos elementos fundamentais do lazer, que são o descanso, o divertimento e o desenvolvimento pessoal e social.

No que tange às emoções presentes no caving evidenciou-se que esta opção de lazer também se configurou como fonte de desenvolvimento dos aspectos sensitivos, possibilitando maior descoberta dos praticantes sobre seu próprio corpo, ou seja, uma possibilidade de conhecimento e reconhecimento de sua corporeidade, de resignificação dos sentidos corporais, proporcionando que a experiência sensorial seja muito mais desenvolvida nela do que em outros ambientes.

Percebe-se que tanto as relações estabelecidas entre os praticantes de caving avaliados e a natureza e os sentidos corporais percebidos por eles se aproximam de um dos valores do lazer preconizados por Dumazedier (1980), o desenvolvimento.

Entretanto, em relação aos significados atribuídos às cavernas, pode-se perceber em alguns depoimentos uma certa busca de evasão das tensões cotidianas, fazendo dessa opção de lazer uma "válvula de escape". O fato de se buscar um descanso, uma aventura alternativa ao cotidiano estressante, não pode se confundir com uma atividade compensatória em relação ao trabalho ou a outras obrigações. As atividades na natureza e o lazer precisam se constituir em si momentos de plena experiência humana de afirmação da vida que podem ser vivenciadas de modo crítico e criativo.

Embora a recuperação e compensação sejam características possíveis de serem vivenciadas no lazer, conforme defendido por Dumazedier (1980) entendemos ser de suma importância questionar o lazer vivenciado sob esta ótica, uma vez que o mesmo não se configura num mecanismo de reação, mas sim de reforço a alienação humana 
(MARCELLINO, 2003), contribuindo para a manutenção do status quo e não para promoção de mudanças.

Vislumbramos então a importância da vivência do caving permeada por uma perspectiva ativa do lazer, marcada pela mudança e não pela manutenção, compactuando assim com a percepção do lazer enquanto fenômeno gerado historicamente e como tempo privilegiado para o surgimento de valores questionadores da ordem social através de sua ocorrência em níveis médios e superiores em que a criticidade e a criatividade sejam traços essenciais, conforme defendido por Marcellino (2002, p. 50). Segundo este autor 'Nessa visão 'crítica' do lazer, detectada entre alguns autores brasileiros, ele não é visto como simples assimilador de tensões, 'válvula de escape', ou alguma coisa boa que ajude a conviver com as injustiças sociais”.

Ainda, a estimulação da vivência do caving na perspectiva crítica e/ou críticacriativa pode contribuir para que essas atividades não se tornem apenas mais um produto da indústria cultural a ser consumido enquanto mercadoria, de forma alienante e predatória, por um público seleto, particularizado, sobretudo, pelo poder econômico de que dispõe, pois conforme expõem Paixão, Costa e Gabriel (2009, p. 369), "seja como forma de manifestação e ou resistência aos novos paradigmas postulados pela pósmodernidade ou ainda como forma de interação homem-natureza rumo à conscientização ecológica, o esporte de aventura assenta-se sob a lógica da produção capitalista".

Sobre esta temática, concordamos com Bahia e Sampaio (2005, p.161) quando as autoras salientam a necessidade de reflexões a respeito da lógica e valores com que as atividades de aventura na natureza vêm sendo vivenciadas, uma vez que "é preciso refletir em que lógica de valores tais atividades têm sido vivenciadas, na medida em que 
é possível romper com a lógica voraz do mercado, com a busca de 'consumo exacerbado', com a vivência alienada do lazer, com a busca de compensação e fuga da realidade, com o 'uso' não sustentável da natureza e com a vivência de valores individualistas".

Torna-se importante que iniciativas sejam criadas com o objetivo de que as atividades esportivas e de lazer junto à natureza sejam praticadas e/ou fruídas em perspectivas críticas e críticas-criativas, as quais proporcione em seus iniciantes e adeptos uma educação pelo lazer no que tange à preservação do meio ambiente e conscientização da interdependência existente entre eles, como também uma educação para o lazer na natureza através da criação de políticas públicas, via programas de democratização ao acesso a esse tipo de lazer.

\section{REFERÊNCIAS}

AULLER, A.; BRANDI, E.; RUBBIOLI, E. As grandes cavernas do Brasil. Belo Horizonte: A. Auler, 2001.

BAHIA, M. C.; SAMPAIO, T. M. V. Turismo de aventura na região amazônica: desafios e potencialidades. In: UVINHA, R. R. (Org.). Turismo de aventura: reflexões e tendências. São Paulo: Aleph, 2005. p. 155-182.

BENOIST, L. Signos e mitos. Belo Horizonte: Interlivros, 1977.

BETRÁN, J. O. Rumo a um novo conceito de ócio ativo e turismo na Espanha: as atividades físicas de aventura na natureza. In: MARINHO, A.; BRUHNS, H. T. Turismo, Lazer e Natureza. Barueri: Manole, 2003. p. 157-202.

BRUHNS, H. T. Lazer e meio ambiente: corpos buscando o verde e a aventura. Revista Brasileira de Ciências do Esporte, Campinas, v. 18, n. 2, p. 86-91, 1997.

BRUHNS, H. T. Lazer e meio ambiente: a natureza com espaço de experiência. Revista Conexões: Educação, Esporte e Lazer, Campinas, n. 3, p. 7-26, 1999.

BRUHNS, H. T. No ritmo da aventura: explorando sensações e emoções. In: MARINHO, A; BRUHNS, H. T. Turismo, lazer e natureza. Barueri: Manole, 2003. p. 29-52. 
BUENO, C. Espeleologia: entenda tudo sobre este esporte. 04 jun. de 2007. Disponível em: http://360graus.terra.com.br/caving/default.asp?did=12881\&action=reportagem $>$. Acesso em: 30 abr. 2008.

CAMACHO, A. S. Las actividades fisicas en la natureza em las sociedades occidentales de final de siglo. Lecturas: Educación Física y Deportes - Revista Digital, Buenos Aires, ano 4, n. 14, p. 1-6, 1999. Disponível em: www.efdeportes.com/efd14/postmod2.htm>. Acesso em: 18 ago. 2006.

CANDIDO, A. As formas de solidariedade. In: OLIVEIRA, P. de S. (Org.). O lúdico na cultura solidária. São Paulo: Hucitec, 2001. p. 89-103.

CARVALHO, Y. M. Lazer e saúde. Brasília: SESI/DN, 2005.

COSTA, V. L. Esportes de Aventura e Risco na Montanha: um mergulho no imaginário. São Paulo: Manole, 2000.

DACOSTA, L. Atlas do esporte no Brasil. Rio de Janeiro: CONFEF, 2006.

DUMAZEDIER, J. Valores e conteúdos culturais do lazer. São Paulo: SESC, 1980.

FERNANDES, R. de C. Esportes Radicais: referências para um estudo acadêmico. Revista Conexões: educação, esporte, lazer, Campinas, v. 1, n.1, p.96-105, 1998.

FERRANS, C. E.; POWERS, M. J. Quality of life of hemodialysis patients. ANNA Journal, v. 20, p. 575-581, 1993.

GARCIA, L. G.; KOWALSKI, M.; ALVES, R. J. A. Lazer e meio ambiente: as práticas educativas e de sensibilização na natureza por meio do lazer e seu potencial na estação de pesquisa, treinamento e educação ambiental - Mata do Paraíso em Viçosa, MG. Licere, Belo Horizonte, v. 12, n. 3, p. 1-31, 2009.

GIL, A. C. Métodos e técnicas de pesquisa social. 3. ed. São Paulo: Atlas, 1991.

LACRUZ, I.; PERICH, M. Lãs emociones em la practica de lãs actividades físicas em la natureza. Lecturas: Educación Física y Deportes. Revista Digital, Buenos Aires, ano 5, n. 23, p. 1-5, 2000. Disponível em: <www.efdeportes.com/efd23/emcnat.htm〉. Acesso em: 18 ago. 2006.

LARSEN, P. Caving. Revista Sport Life, v. 6, n. 68, p. 74, 2007.

LINO, C. F. Cavernas: o fascinante Brasil subterrâneo. São Paulo: Rios, 1989.

MARCELlinO, N. C. Estudos do lazer: uma introdução. 3. ed. Campinas: Autores Associados, 2002.

Lazer e educação. 10. ed. Campinas: Papirus, 2003. 
MAGNANI, J. G. C. Quando o campo é a Cidade: fazendo antropologia na metrópole. In: MAGNANI, J. G. C.; TORRES, L. de L. (Org.). Na Metrópole: texto de antropologia urbana. São Paulo: Editora da Universidade de São Paulo, 1996. p. 12-53.

MARINHO, A. Da Busca pela Natureza aos Ambientes Artificiais: reflexões sobre a escalada esportiva. 2001. 122 f. Dissertação (Mestrado em Educação) - Faculdade de Educação Física. Universidade Estadual de Campinas, Campinas, 2001.

Da aceleração ao pânico de não fazer nada: corpos aventureiros como possibilidades de resistência. In: MARINHO, A.; BRUHNS, H. (Org.). Turismo, Lazer e Natureza. São Paulo: Manole, 2003. p. 1-28.

MARRA, R. J. C. Espeleo Turismo: planejamento e manejo de cavernas. Brasília: Editora WD Ambiental, 2001.

MELO, A. I. G.; FARIA, M. F. Meio Ambiente e Espeleologia: o estudo das cavidades naturais brasileiras. Disponível em: www.mp.sp.gov.br/pls/portal/docs/page/cao_urbanismo_e_meio_ambiente/biblioteca_v irtual/teses de congressos/espeleologia.htm>. Acesso em: 23 dez. 2007.

MORAES, L. C.; OLIVEIRA, D. C. Emoções em situações de risco no alpinismo de alto nível. Revista Brasileira de Psicologia do Esporte e do Exercício, Rio de Janeiro, n. 1, p. 4-21, 2006.

MUNSTER, M. A. Visitando as cavernas do PETAR: a experiência do corpo na natureza. In: ENCONTRO NACIONAL DE RECREAÇÃO E LAZER, 14, 2002, Santa Cruz do Sul. Anais... Santa Cruz do Sul: UNISC, 2002. p. 65-78.

MUNSTER, M. A. V. Esportes na natureza e deficiência visual: uma abordagem pedagógica. 2004. 311 f. Tese (Doutorado em Educação Física) - Faculdade de Educação Física. Universidade Estadual de Campinas, Campinas, 2004.

PAIXÃO, J. A.; COSTA, V. L. de M.; GABRIEL, R. E. C. D. Esporte de aventura e ambiente natural: dimensão preservacional na sociedade de consumo. Motriz, Rio Claro, v. 15, n. 2, p. 367-373, 2009.

PEREIRA, A. S.; PIMENTEL, G. G. de A.; LARA, L. M. Atividades físicas de aventura na natureza: relações entre estilo de vida aventureiro e modo de vida rural para a melhoria da qualidade de vida. Iniciação Científica CESUMAR, v. 6, n. 2, p. 112$119,2004$.

PIMENTEL, G. G. de A.; SAITO, C. F. Caracterização da demanda potencial por atividades de aventura. Motriz, Rio Claro, v. 16, n. 1, p. 152-161, 2010.

RICHARDSON, J. R. Pesquisa Social: métodos e técnica. 3. ed. São Paulo: Atlas, 1999.

SAMPAIO, T. M. V. Educação Física, Lazer e Meio Ambiente: desafios da relação ser humano e ecossistema. In: DE MARCO, A. Educação Física: Cultura e Sociedade. 4. ed. Campinas: Papirus, 2010. p. 87-108. 
SILVA, P. P. C. de; FREITAS, C. M. S. M. Emoções e riscos nas práticas na natureza: uma revisão sistemática. Motriz, Rio Claro, v. 16, n. 1, p. 221-230, 2010.

TAHARA, A. K.; SCHWARTZ, G. M. Atividades de aventura na natureza: investindo na qualidade de vida. Lecturas: Educación Física y Deportes - Revista Digital, Buenos Aires, ano 8, n. 58, p. 1-5, 2003. Disponível em: www.efdeportes.com/efd58/avent.htm>. Acesso em: 17 jul. 2006.

UVINHA, R. R. Juventude, lazer e esportes radicais. São Paulo: Manole, 2001.

Turismo de aventura: uma análise do desenvolvimento desse segmento na Vila de Paranapiacaba. São Paulo: Escola de Comunicação e Artes/ Universidade de São Paulo, 2003.

UVINHA, R. R. Tendências para o turismo de aventura no cenário nacional. In: (Org.). Turismo de aventura: reflexões e tendências. São Paulo: Aleph, 2005. p. 269300 .

\section{Endereço dos Autores:}

Tânia Mara Vieira Sampaio

Universidade Católica de Brasília

QS 07 - Lote 01 EPCT - Águas Claras

Taquatinga - Bloco G - CEP : 71966-700

Endereço Eletrônico: tsampaio@ucb.brou taniamara_sampaio@hotmail.com 